\title{
Psychological Skills and Mindfulness Training Effects on The Psychological Well- being of Undergraduate Music Students: An exploratory Study
}

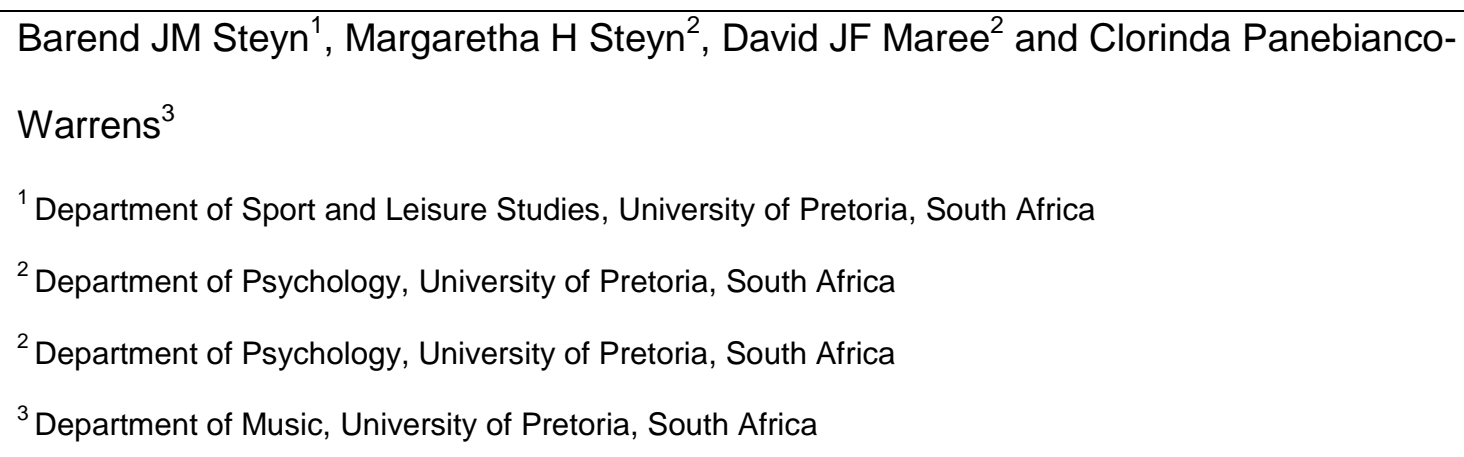

\section{Corresponding author:}

Barend JM Steyn, Department of Sport and Leisure Studies, LC de Villiers Sport Centre, University of Pretoria, Pretoria, 0002, South Africa

Email: ben.steyn@up.ac.za

\section{Abstract}

This study explored the efficacy of psychological skills and mindfulness training intervention on the psychological well-being of undergraduate music students. Participants were undergraduate music students $(n=36)$ from the Department of Music at a South African university, 21 of whom were elected to take the psychological skills and mindfulness training intervention. Data on their self-reported psychological well-being, psychological skills, mindfulness and performance anxiety levels were collected pre- and post-intervention. The analysis applied non-parametric procedures to determine changes in students' psychological well-being after the seven-week intervention program. Findings suggest improvements in psychological well-being, psychological skills, mindfulness and performance anxiety with training. Psychological skills and mindfulness training may have benefits to the psychological well-being of music students. 
Keywords: Psychological well-being, psychological skills training, mindfulness, performance anxiety, music students

\section{Introduction}

Optimal performance in any high performance situation requires psychological well-being (Edwards, Ngcobo, Edwards, \& Palavar, 2005; Lundqvist, 2011; Weinberg \& Gould, 2007). Psychological well-being is a diverse multidimensional concept, with exact components still unknown (Ryff, 1989; Ryff \& Keyes, 1995). Ryff's (1989) research has resulted in the development of objective psychological well-being measurement with components that include autonomy, personal growth, environmental mastery, purpose of life, positive relations with others and self-acceptance. All the psychological constructs employed in this study can be related to psychological well-being (Edwards \& Steyn, 2008). These positive effects of psychosocial well-being on performance have been observed in competitive sporting (Edwards, 2007; Edwards \& Steyn, 2008) and also in the corporate environment due to monetary implications (Luthans, Youssef, Sweetman, \& Harms, 2013; Sørensen \& Holman, 2014). Psychological well-being and high performance cannot be separated. High performance depends on the total availability of the participant of which psychosocial and physical well-being is a prerequisite. For example, a slight headache can impact the quality of performance. The benefit of mindfulness is that it can provide more choice for the participant to maintain optimal availability for high performance in spite of the presence of debilitating factors (Brown, Ryan, \& Creswell, 2007). The link between mindfulness and psychological well-being is fairly well-established in the available literature on mindfulness (Carmody \& Baer, 2008; Shapiro, Brown, Thoresen, \& Plante, 2011; Weinstein, Brown, \& Ryan, 2009).

Musicians experience performance pressures for which supportive mindfulness interventions would be beneficial (Smith, Maragos, \& Van Dyke, 2009). Evidence is needed on how psycho-educational programs and support services might be of benefit to those in high performance operations, including musicians (Tubiana, 2000). This study sought to 
explore if psychological skills with mindfulness training intervention would be protective of health and well-being in a sample of music students in a university department.

According to Smith et al. (2009, p. 135), the professional concert musician may be in a "vulnerable position", due to the high demands and primary energy investment in terms of hours trained (15000 hours) at the expense of neglecting other areas of life such as academic, social and athletic experiences. However, psycho-education in the positive coping strategies such as deep breathing, relaxation, positive self-talk and other psychological skills training (PST) strategies and techniques can be useful to counteract the psychological problems for the musician.

For instance, psycho-educational programs provided early in the musician's career can build psychological well-being capacity and resilience in the positive dimensions of wellbeing (Clark \& Williamon, 2011; Tubiana \& Amadio, 2009). In this instance, psychological skills training that improve performance among athletes can also be employed to improve the musician's ability to perform optimally under pressure (Edwards \& Steyn, 2008). The construct of growth mindset is particularly pertinent with mindfulness education. Growth mindset refers to a mastery orientation where individuals "love learning, they seek challenges, they value effort, and they persist in the face of obstacles" (Dweck, 2000, p. 1).

Combining PST and mindfulness training in one integrated intervention could have multilayer effects on beneficiaries' well-being (Bernier, Thienot, Codron, \& Fournier, 2009). This exploratory study on psychological well-being effects of psychological skills and mindfulness training on undergraduate music students fills an important gap in the research domain of high performance and psychological well-being in performance-evaluative contexts. The question of interest was if the combination of psychological skills and mindfulness training in one combined intervention program could have a positive impact on the psychological well-being of undergraduate music students. 


\section{Method}

\section{Research design}

A quasi-experimental design was used for this study (see Figure 1). This design allowed for the study of psychological well-being effects with the intervention versus control group with no random assignment. A purposive sampling method was used and a voluntary selection method was employed in this study. All undergraduate music students voluntary participated in the experimental and control group of this study.

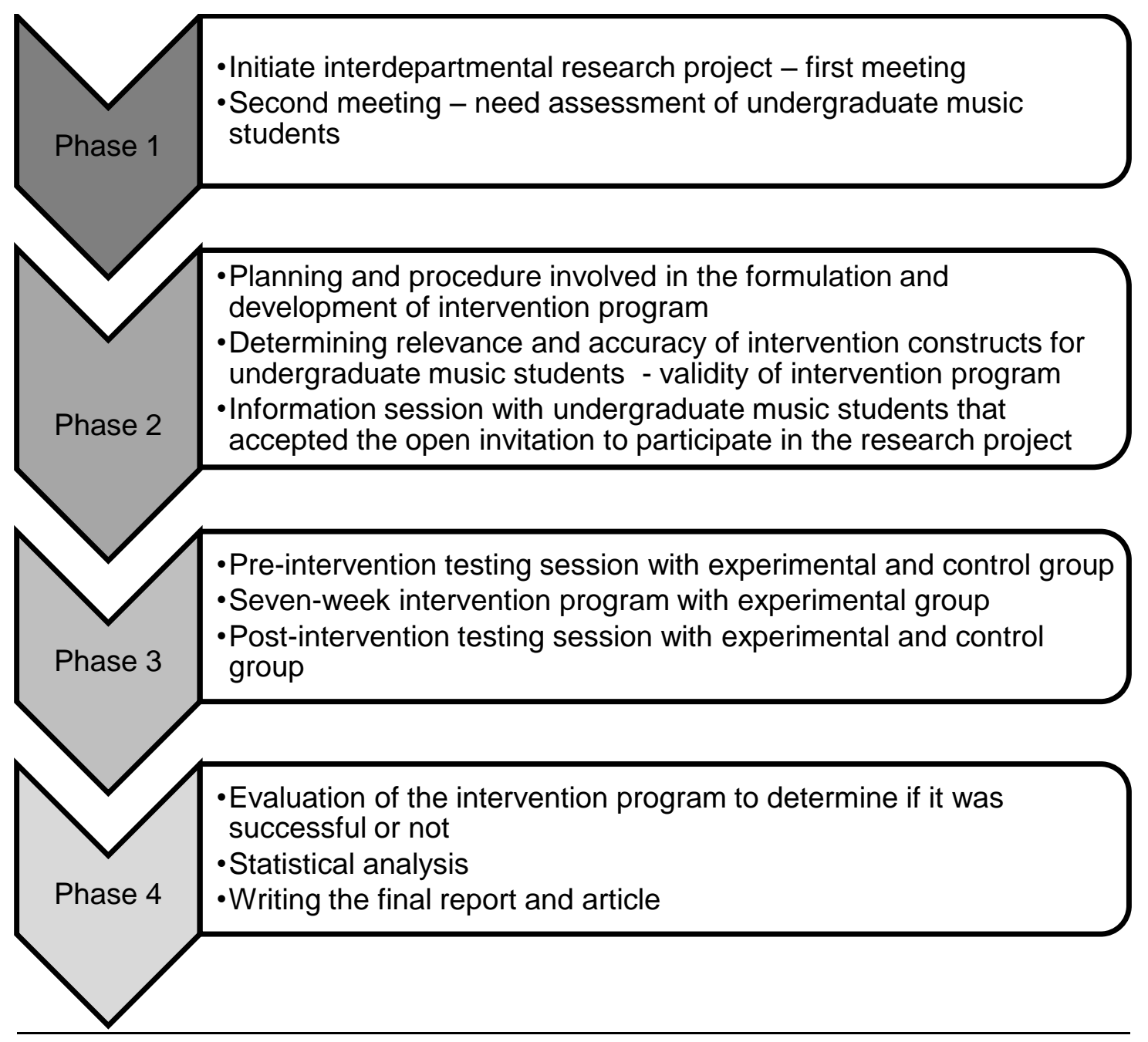

Figure 1: Research design

The needs assessment (the first phase) clearly indicated that performance anxiety is a major problem during high performance music situations. Taking into account that 
performance anxiety and psychological well-being are connected, as well as the fact that PST and mindfulness can improve both psychological well-being and music performance anxiety management, it was therefore decided (in the second stage) that the combination of PST and mindfulness training is the most appropriate intervention approach to mitigate the problem of performance anxiety and improve psychological well-being.

\section{Participants}

A convenience sample of 36 undergraduate music students (females $=58 \%$, males $42 \%$ ) with the Department of Music at a South African university formed the group of participants. A third of the respondents (33\%) were in their first year of study, and $42 \%$ were in the second year. Third-year students constituted $17 \%$ of the sample, and $8 \%$ of the participants were fourth-year students.

The whole spectrum or variety of music art forms was included in this sample. As part of the undergraduate music training of the department, the students are gradually exposed to high-pressure situations such as regular public performances, lunchtime concerts, competitions and practical exams.

\section{Intervention description}

The key psychological and mindfulness components were: training in attention and arousal control and to perform under pressure with psychological centering and different breathing techniques were introduced. Other techniques that were also integrated into the intervention program were goal setting, imagery, psyching up and psyching down skills, self-talk, preperformance routines, mental rehearsal and cognitive restructuring. The importance of perceptions in terms of interpreting the anxiety symptoms as positive, facilitative and constructive was central in the training. A major strong point of the intervention was the influence on perceptions of success and failure (goal orientation), as well as the perception of one's own ability (self-theories) in an incremental fashion (growth mindset). The integration of mindfulness and psychological skills training was the central goal of this 
intervention and the participants were encouraged to maintain high levels of awareness in practicing psychological skills.

\section{Measuring instruments}

The undergraduate music students took psychological well-being measurements and psychological measurements related to psychological well-being including: Ryff's Psychological Well-being Scale (RPWS: Ryff, 1989; Ryff \& Keyes, 1995), Bull's Mental Skills Questionnaire (BMSQ: Bull, Albinson, \& Shambrook, 1996), the Five Facet Mindfulness Questionnaire (FFMQ: Baer et al., 2008), the Competitive State Anxiety Inventory-2 (CSAI-2: Martens, Burton, Vealey, Bump, \& Smith, 1990) and the Self-theory Questionnaire (STQ: Dweck, 2000).

Ryff's Psychological Well-being Scale measures six different dimensions of psychological well-being. High Cronbach alpha coefficients have been reported for scores from the subscales of the measure for autonomy (.83), personal growth (.85), environmental mastery (.86), purpose in life (.88), positive relations with others (.88) and self-acceptance (.91) (Ryff, 1989; Ryff \& Keyes, 1995). See also Edwards, Ngcobo and Pillay (2004), as well as Edwards et al. (2005).

Bull's Mental Skills Questionnaire measures a person's capacity to use his or her mental skills. This questionnaire measures the constructs of mental imagery, mental preparation (goal setting), self-confidence, anxiety and worry management, concentration, relaxation and motivation (Bull et al., 1996).

Previous studies (Bull et al., 1996; Snauwaert, 2001) reported Cronbach's alphas levels of $.80, .64, .62, .61, .59, .72$, and .72 respectively, which are generally acceptable for research purposes.

The Five Facet Mindfulness Questionnaire (FFMQ) assesses five factors of a general tendency to achieve a mindful state in daily life, which includes observing, describing, acting of awareness, a non-judging approach of one's inner experience and non-reactivity to inner experience (Baer et al., 2008). The Cronbach's alpha levels are between .72 and .92 . 
The Competitive State Anxiety Inventory-2 (CSAI-2) measures two different types of anxiety, namely cognitive anxiety and somatic anxiety. It also measures a person's level of self-confidence. Martens et al. (1990) reported Cronbach's alpha scores of between .79 and .90 for this measure.

The Self-theory Questionnaire is a measure of a growth mindset as opposed to a fixed mindset. Previous studies reported acceptable Cronbach alpha values of around .70 (Dweck, 2000; Edwards \& Steyn, 2008; Potgieter \& Steyn, 2010; Smith, 2005).

\section{Procedure}

The Post-graduate and Ethics Committee of the Faculty of Humanities at the University of Pretoria, South Africa granted ethical clearance and approval for this study (Ref Number: 25033779). This study adhered to all the ethical guidelines and requirements of the University of Pretoria.

A comprehensive and detailed information letter was provided to each undergraduate music student who was a potential participant. During the information session, all student queries were addressed and the process was explained before the students were required to sign the informed consent form. The undergraduate music students were also given the option to withdraw from the study at any juncture during the research process without prejudice. Each student created his or her own personal code in order to protect his or her own identity and to ensure confidentiality.

An open invitation was issued to the undergraduate music students after the information session. Once the sample had been finalized, the experimental- as well as the control group underwent the pre-intervention testing session. After the completion of the seven-week intervention program, the same procedure was followed in the post-intervention testing. A quasi-experimental design was implemented in this study to overcome the problems that might arise from the voluntary selection employed in this study (Whitley, 2001). 
Data treatment and statistical analysis

Pre- and post-intervention effects were analysed using the Mann-Whitney $U$ test and the Wilcoxon signed-rank test. The reason why these specific non-parametric statistical procedures were used is because of the purposive sample and the fact that a random sampling method was not employed in this study. The chances of normal distribution of variables, when purposive sampling method is used, are very slight and it is for this reason non-parametric statistical procedure are preferred. With these limitations, it is better to use non-parametric statistical procedures that are not based on underlying distributions (Urden, 2010).

\section{Results}

\section{Psychological well-being effects}

Psychological well-being improved with the interventions for "positive relations with others" $(p=.020)$ and also the psychological skills of self-confidence $(p=.017)$; anxiety and worry management $(p=.017)$; concentration $(p=.002)$; relaxation $(p=.002)$; and motivation $(p=$ .002) (see Table 1$)$. Similarly cognitive state anxiety $(p=.012)$ and somatic state anxiety ( $p$ $=.003)$ decreased significantly, while state self-confidence $(p=.045)$ increased significantly in the post-intervention test scores (see Table 1). A significant change in the intervention group was also observed in the mindfulness factors of "describe" $(p=.028)$ and "non-judge" $(p=.011)$. The control group, which did not undergo any intervention, did not display any significant changes in scores.

The growth mindset became stronger after the intervention program $(p=0.027)$, while the fixed mindset $(p=0.001)$ decreased significantly from the pre- and post-intervention testing. Within the control group, there was one significant change from the pre- and postintervention testing, namely the fixed mindset $(p=0.028)$ decreased significantly from preand post-intervention testing. 
Table 1: Mean scores (standard deviation) for the experimental (EG) group and control (CG) group and $p$ values from the Wilcoxon signed-rank test

\begin{tabular}{lllll}
\hline \multicolumn{1}{c}{ Psychological } & Group & Pre-Intervention & Post-Intervention & $\boldsymbol{p}$ \\
\hline \multicolumn{1}{c}{ measurements } & & & & \\
\hline Positive relations with others & EG & $11.752(3.859)$ & $13.095(2.809)$ & .020 \\
Self-confidence & EG & $14.000(4.757)$ & $15.571(3.867)$ & .017 \\
Anxiety and worry & EG & $10.095(4.711)$ & $13.476(5.400)$ & $\mathbf{. 0 1 7}$ \\
Concentration ability & EG & $13.316(4.498)$ & $16.476(5.202)$ & $\mathbf{. 0 0 2}$ \\
Relaxation ability & EG & $12.857(6.506)$ & $16.381(4.620)$ & $\mathbf{. 0 0 2}$ \\
Motivation & EG & $14.667(5.151)$ & $18.190(3.995)$ & $\mathbf{. 0 0 2}$ \\
Describe & EG & $28.000(7.108)$ & $31.143(7.479)$ & $\mathbf{. 0 2 8}$ \\
Non-judge & EG & $21.750(6.592)$ & $25.714(5.746)$ & $\mathbf{. 0 1 1}$ \\
State cognitive anxiety & EG & $25.619(5.962)$ & $21.762(5.558)$ & $\mathbf{. 0 1 2}$ \\
State somatic anxiety & EG & $25.524(7.672)$ & $20.857(6.770)$ & $\mathbf{. 0 0 3}$ \\
State self-confidence & EG & $21.286(7.695)$ & $24.143(6.429)$ & $\mathbf{. 0 4 5}$ \\
Growth mindset & EG & $15.905(1.895)$ & $17.048(1.396)$ & $\mathbf{. 0 2 7}$ \\
Fixed mindset & EG & $8.000(2.074)$ & $6.381(1.802)$ & $\mathbf{. 0 0 1}$ \\
Fixed mindset & CG & $7.533(2.748)$ & $6.214(2.007)$ & $\mathbf{. 0 2 8}$ \\
\hline
\end{tabular}

Note. The results from the Wilcoxon signed-rank test which include the mean scores of the experimental and control groups, standard deviation of pre- and post-intervention testing and $p$ values. Only the significant $p$ values (bold) are indicated in this table

\section{Discussion and conclusion}

The primary aim of this study was to determine if the intervention program aimed at improving psychological well-being in student musicians has efficacy. A limitation of the study was the fact that a quasi-experimental design was implemented and the experimentaland control group was not selected randomly.

Findings suggest overall psychological well-being improvement with exposure to a mindfulness oriented psycho-educational program for positive relations with others. This 
finding is in line with the research of Edwards and Steyn (2008) and Gardner and Moore (2004) who reported mindfulness education to support positive health in high performing activity settings.

This effect is likely from improvements in mindfulness with increased levels of psychological well-being. Improvement in the growth mindset, which is also a positive psychological indicator, was observed in the intervention group. The extensive research of Dweck (2000) on self-theories confirms that improvement in the growth mindset leads to multilayer psychological benefits and psychological well-being. Recent research by Hanley et al. (2015) suggests that mindful individuals are less biased towards themselves and maintain their self-concepts with less interference from past associations or preconceived notions.

Self-confidence levels increased significantly between the pre- and post-intervention test measurements. These findings suggest self-confidence to be positively influenced with mindfulness training. This relationship between mindfulness and self-confidence still needs further research. However, the research of Sedas (2015) suggests that experiential learning that is accompanied by high levels of awareness (mindfulness) can positively impact on selfconfidence.

In conclusion, psychological skills for mindfulness training appear to have potential as a resource to improve psychological well-being for managing performance anxiety during high performance activity.

\section{References}

Baer, R. A., Smith, G. T., Lykins, E., Button, D., Krietemeyer, J., Sauer, S., ...Williams, J. M. G. (2008). Construct validity of the Five Facet Mindfulness Questionnaire in meditating and nonmeditating sample. Assessment, 15(3), 329-342.

Bernier, M., Thienot, E., Codron, R., \& Fournier, J. F. (2009). Mindfulness and acceptance approaches in sport performance. Journal of Clinical Sports Psychology, 4, 320-333. 
Brown, K. W., Ryan, R. M., \& Creswell, J. D. (2007). Mindfulness: Theoretical foundations and evidence for its salutary effects. Psychological Inquiry, 18(4), 211-237.

Bull, S., Albinson, J., \& Shambrook, C. (1996). The mental game plan. Getting psyched for sport. Eastbourne, UK: Sports Dynamics.

Carmody, J., \& Baer, R. A. (2008). Relationships between mindfulness practice and levels of mindfulness, medical and psychological symptoms and well-being in a mindfulnessbased stress reduction program. Journal of Behavioural Medicine, 31, 23-33.

Clark, T., \& Williamon, A. (2011). Evaluation of a mental skills training program for musicians. Journal of Applied Sport Psychology, 23(3), 324-359.

Dweck, C. S. (2000). Self-theories: Their role in motivation, personality, and development. Philadelphia, PA: Taylor and Francis.

Edwards, D. J. (2007). Sport psychological skills training and psychological well-being in youth athletes. (Unpublished doctoral dissertation). Department of Biokinetics, Sport and Leisure Sciences, University of Pretoria, Pretoria.

Edwards, S. D., Ngcobo, H. S. B., Edwards, D. J., \& Palavar, K. (2005). Exploring the relationship between physical activity, psychological well-being and physical selfperception in a group of regular exercisers. South African Journal for Research in Sport, Physical Education and Recreation, 27(1), 75-90.

Edwards, D. J., Ngcobo, H. S. B., \& Pillay, A. L. (2004). Psychological well-being in South African students. Psychological Reports, 95, 1279-1282.

Edwards, D. J., \& Steyn, B. J. M. (2008). Sport psychological skills training and psychological well-being. South African Journal of Research in Sport, Physical Education and Recreation, 30(1), 15-28.

Gardner, F. L., \& Moore, Z. E. (2004). A mindfulness-acceptance-commitment (MAC) based approach to performance enhancement: Theoretical considerations. Behavior Therapy, 35, 707-723.

Hanley, A., Garland, E., Canto, A., Warner, A., Hanley, R., Dehili, V., \& Proctor, A. (2015). Dispositional mindfulness and bias in self-theories. Mindfulness, 6(2), 202-207. 
Lundqvist, C. (2011). Well-being in competitive sports-the-feel-good factor? A review of conceptual considerations of well-being. International Review of Sport and Exercise Psychology, 4(2), 109-127.

Luthans, F., Youssef, C. M., Sweetman, D. S., \& Harms, P. D. (2013). Meeting the leadership challenge of employee well-being through relationship psycap and health psycap. Journal of Leadership \& Organizational Studies, 20(1), 118-133.

Martens, R., Burton, D., Vealey, R. S., Bump, L., \& Smith, D. (1990). The development of the Competitive State Anxiety Inventory-2 (CSAI-2). In R. Martens, R. S. Vealey, \& D. Burton (Eds.), Competitive anxiety in sport (pp. 117-190). Champaign, IL: Human Kinetics.

Potgieter, R. D., \& Steyn, B. J. M. (2010). Goal orientation, self-theories and reactions to success and failure in competitive sport. African Journal for Physical, Health Education, Recreation and Dance, 16(4), 642-657.

Ryff, C. D. (1989). Happiness is everything, or is it? Explorations on the meaning of psychological well-being. Journal of Personality and Social Psychology, 57, 10691081.

Ryff, C. D., \& Keyes, C. L. M. (1995). The structure of psychological well-being revisited. Journal of Personality and Social Psychology, 69, 719-727.

Sedas, S. W. (2015). A program to develop resiliency, self-confidence, intrinsic motivation, and a sense of purpose in young adults. Vol 122. Proceedings of the ASEE Annual Conference and Exposition: Making value for society. 14 June to 17 June, Washington Convention Centre, Seattle, United States.

Shapiro, S. L., Brown, K. W., Thoresen, C. E., \& Plante, T. G. (2011). The moderation of Mindfulness-based Stress Reduction effects by trait mindfulness: Results from a randomized controlled trail. Journal of Clinical Psychology, 67(3), 267-277. 
Smith, B. P. (2005). Goal orientation, implicit theory of ability, and collegiate instrumental music practice. Psychology of Music, 33(1), 36-57.

Smith, A. M., Maragos, A., \& Van Dyke, A. (2009). Psychology of the musician. In R. Tubiana \& P. C. Amadio (Eds.), Medical problems of the instrumentalist musician (pp. 135-170). New York, NY: Informa Healthcare, Inc.

Snauwaert, E. (2001). A psychometric evaluation of Bull's Mental Skills Questionnaire: A study on Flemish students. Vol 5 (pp. 23-25). Proceedings of the $10^{\text {th }}$ World Congress of Sport Psychology, May 28 to June 2, Skiathos. Thessaloniki, Greece: Christodoulidi.

Sørensen, O. H., \& Holman, D. (2014). A participative intervention to improve employee well-being in knowledge work jobs: A mixed-methods evaluation study. Work \& Stress: An International Journal of Work, Health \& Organisations, 28(1), 67-86.

Tubiana, R. (2000). Functional anatomy. In R. Tubiana \& P. C. Amadio (Eds.), Medical problems of the instrumentalist musician (pp. 1-4). New York, NY: Informa Healthcare, Inc.

Tubiana, R., \& Amadio, P. C. (2009). Medical problems of the instrumentalist musician. New York, NY: Informa Healthcare, Inc.

Urden, T. C. (2010). Statistics in plain English ( $3^{\text {rd }}$ ed.). New York, NY: Routledge Taylor and Francis.

Weinberg, R. S., \& Gould, D. (2007). Foundations of sport and exercise psychology ( $4^{\text {th }}$ ed.). Champaign, IL: Human Kinetics.

Weinstein, N., Brown, K. W., \& Ryan, R. M. (2009). A multi-method examination of the effects of mindfulness on stress attribution, coping, and emotional well-being. Journal of Research in Personality, 43, 374-385.

Whitley, B. E. (2001). Principles of research in behavioural science ( $2^{\text {nd }}$ ed.). New York, NY: McGraw-Hill. 